\title{
O avanço da Covid-19 e o isolamento social como estratégia para redução da vulnerabilidade
}

o avanço da Covid-19 e o isolamento social como estratégia para redução da vulnerabilidade

L'avancement du Covid-19 et l'isolement social en tant que stratégie pour la réduction de la vulnerabilité

El avance de Covid-19 y el aislamiento social como estrategia para reducir la vulnerabilidad.

The advancement of Covid-19 and social isolation as a strategy to reduce vulnerability

\section{Heitor Soares de Farias}

\section{(2) OpenEdition Journals}

Edição electrónica

URL: http://journals.openedition.org/espacoeconomia/11357

DOI: $10.4000 /$ espacoeconomia. 11357

ISSN: 2317-7837

Editora

Núcleo de Pesquisa Espaço \& Economia

\section{Refêrencia eletrónica}

Heitor Soares de Farias, " 0 avanço da Covid-19 e o isolamento social como estratégia para redução da vulnerabilidade », Espaço e Economia [Online], 17| 2020, posto online no dia 08 abril 2020

consultado o 21 dezembro 2020. URL : http://journals.openedition.org/espacoeconomia/11357 ; DOI https://doi.org/10.4000/espacoeconomia.11357

Este documento foi criado de forma automática no dia 21 dezembro 2020.

\section{(c) (†) (-)}

Espaço e Economia - Revista brasileira de geografia econômica est mise à disposition selon les termes de la licence Creative Commons Attribution - Pas d'Utilisation Commerciale - Partage dans les Mêmes Conditions 4.0 International. 


\title{
O avanço da Covid-19 e o isolamento social como estratégia para redução da vulnerabilidade
}

\author{
O avanço da Covid-19 e o isolamento social como estratégia para redução da \\ vulnerabilidade \\ L'avancement du Covid-19 et l'isolement social en tant que stratégie pour la \\ réduction de la vulnerabilité \\ El avance de Covid-19 y el aislamiento social como estrategia para reducir la \\ vulnerabilidad. \\ The advancement of Covid-19 and social isolation as a strategy to reduce \\ vulnerability
}

Heitor Soares de Farias

\section{Uma breve retrospectiva}

1 Dia 26 de março de 2020, um mês após ser registrado o primeiro caso de COVID-19 no Brasil, são 2433 casos confirmados, 59 mortes e surgiram 284 novos casos nas últimas 24 horas $^{1}$. O objetivo deste texto é fazer uma breve retrospectiva da disseminação dessa doença até ser declarada uma pandemia, pela Organização Mundial da Saúde (OMS), e pensar em perspectivas futuras.

2 O Coronavírus é uma família de vírus que causa infecções respiratórias, conhecida desde a década de 1960. Um novo coronavírus foi descoberto em 31/12/19, após casos registrados em Wuhan, na China, e a doença foi chamada de Covid-19 ou Sars-Cov- $2^{2}$. Embora comecem a aparecer evidências de que a China omitiu informações iniciais sobre a nova doença, e com isso perderam tempo precioso na divulgação dos fatos, o que poderia impedir que mais pessoas se contaminassem, em um momento seguinte de maior transparência, o governo conseguiu que a epidemia ficasse restrita à província de Hubei, onde está Wuhan ${ }^{3}$. 
3 Embora os sintomas se assemelhem aos da gripe (febre, dor de cabeça, dor no corpo e tosse seca), trata-se de uma pneumonia forte com sério comprometimento da capacidade respiratória. Segundo a Organização Mundial de Saúde, os casos leves são aqueles sem pneumonia, ou com uma pneumonia branda, e respondem por $80,9 \%$ dos registros. Os classificados como severos são aqueles em que o paciente apresenta falta de ar, mudança na frequência respiratória, saturação de oxigênio no sangue, infiltração pulmonar e síndrome respiratória aguda, e representam 13,8\% dos registros. Já os casos críticos, respondem por 4,7\% das infecções. A letalidade da Covid-19 é baixa, mas tem capacidade de transmissão muito alta o que eleva muito o número de óbitos ${ }^{4}$.

4 A medida adotada é o distanciamento social, evitando aglomerações a fim de manter uma distância mínima de um metro e meio para outras pessoas. Em casos extremos é adotado o isolamento social, quando as pessoas não podem sair de suas casas para impedir a propagação do vírus. Já os suspeitos de infecção devem ficar de quarentena por quatorze dias, que é o período de incubação, tempo para o vírus se manifestar no corpo $^{5}$. A doença transformou a cidade chinesa em um epicentro, com um grande número de casos surgindo rapidamente. Um verdadeiro desespero compartilhado por cerca de quarenta brasileiros que estavam na região mais crítica da então epidemia, que passaram a ficar isolados implorando serem resgatados pelo governo brasileiro ${ }^{6}$.

No dia 4 de fevereiro, o presidente Jair Bolsonaro declarou estado de emergência, e o governo passou a planejar a operação de resgate. Isso exigia colocar militares na área de risco e trazer pessoas com potencial infecção para o solo brasileiro, uma ação arriscada. $O$ resgate foi realizado e os envolvidos passaram por quarentena, mas a partir de então quase nada mais mudou' . Nenhuma outra medida foi tomada, muito provavelmente desacreditando no avanço da epidemia para além do sudeste asiático. Sentimento compartilhado por outros chefes de estado do ocidente, imaginando, equivocadamente, que o problema ficaria por lá, com destaque para os Estados Unidos, Reino Unido, Itália...

6 Essa imobilidade pode ter sido motivada pelo empenho que a China dedicava na contenção da epidemia, construindo em 10 dias um hospital com mil leitos para os infectados com o coronavírus ${ }^{8}$. Além disso, a Coreia do Sul, país vizinho atingido na sequência, obteve sucesso em controlar a epidemia, baseando-se na multiplicação de testes diagnóstico realizados massivamente para identificação dos indivíduos infectados, colocando-os em quarentena para interromper o avanço da doença9.

7 Entretanto, a experiência anterior com a H1N1, no ano de 2009, com uma capacidade de transmissão muito inferior ao coronavírus, já tinha mostrado que em um mundo globalizado, com pessoas viajando o tempo todo, fica praticamente impossível impedir que novas doenças cheguem a outros países. Assim, em 23 de fevereiro a Itália registrou o primeiro caso e em poucas semanas se transformou em um novo epicentro da Covid-19. Podem ser apontados vários motivos para isso como o clima frio, população com grande número de idosos, mas principalmente a postura dos italianos em decidir não cumprir o isolamento social indicado pela $\mathrm{OMS}^{10}$.

8 Milão chegou a adotar como slogan oficial "Milano Non Si Ferma" (Milão Não Para), a fim de que a população não se confinasse em suas casas atingindo negativamente a economia. A vida agitada foi mantida e as recomendações para evitarem aglomerações foram ignoradas. Nem o campeonato de futebol parou. Cerca de 40 mil fãs viajaram para Milão para acompanhar a partida entre Atalanta e Valencia, e podem ter se contaminado de forma coletiva. O vírus rapidamente se espalhou e os números de 
infectados e de mortos dispararam ${ }^{11}$. A Itália ultrapassou a China em óbitos, atingindo uma letalidade de $10 \%$, muito superior à média mundial. Nas últimas 24 horas morreram quase mil pessoas, somando mais de nove mil mortes no total, metade em Milão ${ }^{12}$.

9 Apesar disso, mais de $80 \%$ das mortes na Itália continuam acontecendo nas mesmas três regiões, e os demais territórios continuam com taxas muito baixas. $O$ intenso trânsito de pessoas pela União Europeia fez com que a Espanha fosse atingida. Esta, mais integrada ao fluxo de circulação de pessoas que a Itália, com diferenças gritantes entre o norte e o sul, acabou permitindo a grande dispersão geográfica e passou a apresentar muitos casos de Covid-19 com mortos. A Espanha levou apenas três dias para duplicar as primeiras 1.000 mortes registradas. Um ritmo mais intenso do que a China e a Itália alcançaram ${ }^{13}$.

10 Em 11 de março a OMS declarou a pandemia do novo coronavírus, porque nas últimas duas semanas o número de casos de Covid-19 fora da China aumentou 13 vezes e a quantidade de países afetados triplicou. São muitas pessoas infectadas em 114 nações, sendo que 4291 pessoas morreram, justificou Tedros Ghebreyesus, diretor-geral da $\mathrm{OMS}^{14}$. Hoje, três semanas depois, já são mais de 50000 mortos no mundo ${ }^{15}$. A definição de pandemia não depende de um número específico de casos. Considera-se que uma doença infecciosa atingiu esse patamar quando afeta um grande número de pessoas espalhadas pelo mundo. A OMS evita usar o termo com frequência para não causar pânico ou uma sensação de que nada pode ser feito para controlar a enfermidade ${ }^{16}$.

11 A partir de então Trump e Boris Johnson mudaram seus discursos negacionistas e começaram a agir promovendo o isolamento social, mesmo já tendo passado mais de um mês da identificação dos primeiros casos em seus países. No entanto, muito tempo já tinha sido desperdiçado e nos EUA se formou um novo epicentro, e com mais de 275 mil casos confirmados superou a China em número de infectados. Trump justificou dizendo que o aumento é reflexo do grande número de testes realizados recentemente, entretanto no país foram 1480 mortes nas últimas 24 horas, o maior número diário em um país desde o início da epidemia ${ }^{17}$. No Reino Unidos a Covid-19 também avança e hoje, Boris Jonhson declarou estar com a doença, o primeiro chefe de estado até o momento ${ }^{18}$.

\section{A situação no Brasil}

No dia 26 de fevereiro foi anunciado o primeiro paciente diagnosticado com a Covid-19 no país. Um homem de 61 anos, vindo da Itália, foi internado em São Paulo com os sintomas característicos ${ }^{19}$. Uma semana depois, no dia 5 de março, São Paulo tinha dez dos treze casos de Covid-19 no Brasil, quando foi notificado o primeiro no Rio de Janeiro $^{20}$. Já era esperado que São Paulo e Rio de Janeiro apresentassem os primeiros casos no Brasil, pois possuem as cidades mais ricas do país, mais populosas e concentram maior número de voos internacionais ${ }^{21}$.

Os infectados retornaram de viagens internacionais, muitos da Itália, e pertencem às classes sociais mais abastadas, tendo em vista o alto custo das passagens aéreas junto a desvalorização de nossa moeda no último ano. 0 coronavírus ficou circulando entre essas pessoas de maior poder aquisitivo, muitas delas assintomáticas, ou com sintomas muito leves, que não usam transporte público de massa e assim conseguem evitar aglomerações ${ }^{22}$. Uma semana após o primeiro caso de Covid-19, o estado do Rio de 
Janeiro contabilizava 15 ocorrências, e seu mapeamento concentrava esses números na Zona Sul e Barra da Tijuca, áreas nobres da cidade do Rio de Janeiro ${ }^{23}$.

Um desses casos foi a partir da transmissão local, ou seja, pessoa que se infectou sem que tivesse ido aos países com registro da doença, mas que teve contato com outra pessoa infectada, que trouxe o vírus de fora do país ${ }^{24}$. Diante desse fato e da inércia do governo federal, no dia 13 de março, o governador do Rio de Janeiro, Wilson Witzel, decretou o fechamento de escolas, teatros e cinemas, além de atividades que proporcionassem aglomerações como a visitação a presos e a realização de eventos esportivos, eventos científicos, comícios e passeatas por 15 dias. Foi criado um gabinete de crise para monitorar os desdobramentos da propagação do vírus 24 horas por dia ${ }^{25}$. $\mathrm{Na}$ sequência, instituições de ensino municipais e federais localizadas no estado anunciaram a antecipação das férias escolares.

Na mesma semana, no dia 19 de março, ocorreu a primeira morte em consequência do coronavírus no estado do Rio de Janeiro. Uma mulher de 63 anos residente no interior do estado, município de Miguel Pereira, que trabalhava como doméstica no Leblon, Zona Sul do Rio de Janeiro. Sua patroa, que tinha viajado para a Itália, achava que estava doente, mas não avisou a ela ${ }^{26}$. A notícia da morte fez o governador endurecer ainda mais as restrições, proibindo por 15 dias a população de frequentar às praias, lagoas e piscinas públicas. Decretou o fechamento de bares, restaurantes e lanchonetes, pontos turísticos, sendo mantidas somente as atividades essenciais ${ }^{27}$.

16 Foi decretado impedido o transporte de passageiros, por terra e ar, entre os estados de São Paulo, Minas Gerais, Espirito Santo, Bahia e Distrito Federal. Suspendeu também o transporte entre a capital e os municípios da região metropolitana e destes com o interior. Proibiu o desembarque por passageiros nos aeroportos, a atracação de navios de cruzeiro de estados e países com circulação confirmada de coronavírus. Sendo que a competência dessas atividades é do governo federal, através de suas agências reguladoras, e dependia da anuência de ambas para serem confirmadas ${ }^{28}$.

17 O objetivo desses decretos é interromper a transmissão do vírus para que o sistema de saúde não seja sobrecarregado. Muitos serão infectados, infelizmente, mas se a procura pelo sistema de saúde for mais espaçada no tempo, haverá mais e melhores condições de atendimento. Descumprir o isolamento aumenta a transmissão de maneira muito rápida e, por consequência, aumenta e muito a procura por socorro, podendo faltar leitos e respiradores para os doentes, caracterizando o colapso do sistema de saúde ${ }^{29}$.

18 As medidas adotadas no Rio de Janeiro foram seguidas por outros governadores, que há tempos vêm agindo coordenadamente em bloco, como também pelos prefeitos que replicaram as medidas para os municípios ${ }^{30}$, fechando o comércio em geral, o que afrontou Jair Bolsonaro. 0 presidente tem tentado transparecer que a Covid-19 não é tão agressiva, chamando de histeria o que está sendo veiculado pela mídia ${ }^{31}$. Recentemente visitou os EUA e voltou com suspeita de infecção, depois que 23 membros de sua comitiva atestarem positivo para o coronavírus ${ }^{32}$. Disse ter atestado negativo, mas foi colocado em quarentena até que repetisse o exame. Através das redes sociais estimulou passeatas e rompeu o isolamento para cumprimentar apoiadores, menosprezando o risco de transmissão da Covid-19, a quem chamou de gripezinha ${ }^{33}$.

19 A principal preocupação do governo federal é que o isolamento da população acentue a crise econômica. Sua postura tem sido de estimular que os cidadãos voltem às ruas e levem uma vida normal, o que contraria as recomendações da OMS e até mesmo do próprio ministro da saúde, Luiz Henrique Mandetta, que pede para a população ficar 
em casa $^{34}$. A crise econômica é certa, e não ocorrerá pela imobilidade do cidadão brasileiro, impedido de ir ao trabalho, mas pela dimensão mundial dos estragos econômicos causados pela pandemia do coronavírus em diferentes países. Hoje, mais de um terço da população mundial está em isolamento social ${ }^{35}$.

O passo seguinte do governo foi o lançamento da campanha "O Brasil não pode parar", que teve circulação impedida pela justiça ${ }^{36}$. A postura do governo federal dificulta e até impede que a população se mantenha fora das ruas. Os quase 40 milhões de trabalhadores informais estão em suas casas, sem nenhum rendimento, veem no discurso do presidente um estímulo a romper o isolamento decretado pelos governos estaduais ${ }^{37}$. Como manter em suas casas essas pessoas que dependem do ganho diário para se alimentar?

21 Somente na segunda semana de isolamento decretado no Rio de Janeiro, a câmara dos deputados, em Brasília, aprovou o valor de $\mathrm{R} \$ 600,00$ para os trabalhadores informais, podendo chegar a $\mathrm{R} \$ 1200,00$ por família. Uma vitória da oposição, tendo em vista que a proposta inicial do governo federal era de $\mathrm{R} \$ 200,00$. No entanto, só na segunda-feira a pauta passou pelo senado e ainda precisa ser assinado pelo presidente da república ${ }^{38}$. Quanto tempo mais será necessário para esses valores cheguem às mãos de quem precisa? Essa resposta vem tardiamente para quem precisa decidir se morre de Covid-19 ou morre de fome.

Muitos dos serviços essenciais que continuam funcionando (supermercados e farmácias) têm controlado a entrada da população nos estabelecimentos, não mais preocupados com a saúde, mas com a segurança ${ }^{39}$. A prática de arrastão, quando pessoas em grupos invadem os estabelecimentos levando os produtos sem pagar, vem ocorrendo nas periferias. Parte da população teme a convulsão social, pois não só trabalhadores informais precisam de apoio do governo, empresários também precisam para manter os postos de trabalho, ou o desemprego crescerá ${ }^{40}$. Diante da lentidão das decisões sobre a ajuda financeira começam a pulular carreatas, manifestações da classe média alta pressionando pelo fim do confinamento e retorno das atividades ${ }^{41}$. Em meio a esse cenário governadores renovam o isolamento por mais $15 \mathrm{dias}^{42}$.

\section{Considerações finais}

23 Hoje, 3 de abril, no Brasil são 9056 casos confirmados com 356. Em uma semana, enquanto escrevia este texto, já se foram mais os casos confirmados quase quadruplicaram e as mortes mais que quintuplicaram. Há quem afirme que os dados estão subestimados e somente $10 \%$ estariam sendo notificados. Faltam testes para verificação da Covid-19 nos pacientes e muitos morrem sem serem testados. Aqueles que são testados demoram 10 dias, em média, para receber o resultado, o que faz aumentar o número de suspeitas de infecçãa ${ }^{43}$. Em São Paulo, no dia 1 de abril havia 201 corpos aguardando o resultado do exame ${ }^{44}$.

24 A realização de testes em massa é fundamental para o cumprimento das funções de vigilância epidemiológica que depende da disponibilidade de dados. Informações como o número de infectados e de óbitos em decorrência do coronavírus, junto a sua localização são essenciais para identificar a distribuição e a gravidade da epidemia. $\mathrm{Na}$ indisponibilidade dessas informações, que dificultam sua utilização na vigilância epidemiológica, a imprensa tem papel relevante em emitir o primeiro alerta sobre a 
ocorrência de uma epidemia, devendo haver a realização da investigação para confirmação ou não ${ }^{45}$.

A informação também é fundamental para a população, pois a divulgação, desde maneiras de manter a higiene até a necessidade do isolamento, ajuda na prevenção, o que reduz a vulnerabilidade. 0 vulnerável é aquele que está mais suscetível a ser infectado, uma vez que possui desvantagens para a mobilidade social não alcançando patamares mais elevados de qualidade de vida em função de sua cidadania fragilizada ${ }^{46}$. Isso ocorre porque a distribuição da saúde e da doença em uma sociedade não é aleatória, estando associada à posição social, que por sua vez define as condições de vida e de trabalho dos indivíduos e grupos ${ }^{47}$. Fatores socioeconômicos, que compõem os determinantes sociais em saúde, influenciam a ocorrência de problemas de saúde e nos fatores de risco na população ${ }^{48}$.

Isso significa que a Covid-19 pode alcançar um número muito maior de infectados e de mortos ao se instalar nas áreas mais pobres do país: onde falta saneamento básico, principalmente água limpa para lavar as mãos; onde falta renda, e por isso as pessoas têm que se arriscar a descumprir o isolamento social para garantir alguns sustento para a família, onde falta o Estado, e o sistema de saúde apresenta fragilidades. Nesse sentido, a informação divulgada nos meios de comunicação reforçando a necessidade da população ficar em casa, junto ao programa de ajuda financeira do governo, são fundamentais para reduzir a exposição dos grupos mais vulneráveis.

No estado do Rio de Janeiro são 1074 casos confirmados e 47 mortes, enquanto no estado de São Paulo são 4048 casos e 219 mortes, seis vezes mais mortes do que a China, considerando os 13 dias após o primeiro registro de óbito por Covid-1949. Ao que parece a rápida ação do governador do Rio de Janeiro tem surtido o efeito desejado - São Paulo registrou casos antes e decretou isolamento depois -, entretanto, o isolamento social é apenas uma medida paliativa. Mesmo na China, onde foram tomadas medidas muito duras com restrições severas à circulação de pessoas, e se conseguiu zerar os casos de transmissão local da Covid-19, o retorno de chineses que estavam fora do país no início da epidemia fez aparecer novamente casos da doença ${ }^{50}$.

Neste momento, a China, que controlou o surto inicial, enquanto tenta voltar lentamente à vida normal, atua para evitar uma nova onda de infecção, mesmo que branda, a partir dos casos vindos do exterior. Precisamos de ações internacionais coordenadas de isolamento social junto a realização de testes a fim de detectar quem precisa estar em quarentena, para evitar que o coronavírus volte a se manifestar onde a transmissão conseguiu ser interrompida. Somente o isolamento social pode não ser eficaz a médio prazo, devendo ser encarado, sobretudo, como uma medida para ganhar tempo enquanto cientistas do mundo estão à procura de tratamento e cura da Covid-19, pois vacina exige mais experimentação. 


\section{NOTAS}

1. JORNAL O DIA. Casos e mortes por coronavírus no Brasil. O Dia, Rio de Janeiro, Pandemia do Coronavírus, 26.03.2020. Disponível em: https://odia.ig.com.br/mundo-e-ciencia/coronavirus/ mapa. Acessado em: 26 de março de 2020.

2. BRASIL. Ministério da Saúde. O que é coronavírus? (COVID-19). Disponível em: https:// coronavirus.saude.gov.br/. Acessado em: 26 de março de 2020.

3. HARVEY, D. Política anticapitalista em tempos de covid-19. In: DAVIS, M., et al: Coronavírus e a luta de classes. Terra sem Amos: Brasil, 2020. Disponível em: https:// terrasemamos.files.wordpress.com/2020/03/coronavc3adrus-e-a-luta-de-classes-tsa.pdf. Acessado em: 28 de março de 2020.

4. REVISTA VEJA. Coronavírus: apenas $5 \%$ dos casos são graves, diz OMS. Revista Veja, São Paulo, Saúde. 18.02.2020. Disponível em: https://veja.abril.com.br/saude/coronavirus-apenas-5-doscasos-sao-graves-diz-oms/. Acessado em: 28 de março de 2020.

5. BRASIL. Ministério da Saúde. Como é definido um caso suspeito de coronavírus?. Disponível em: https://coronavirus.saude.gov.br/sobre-a-doenca\#tratamento. Acessado em: 28 de março de 2020.

6. LOPES, Elizabeth. Quarentena de brasileiros que virão de Wuhan será em Anápolis, Florianópolis ou Nordeste, diz Onyx. O Estado de São Paulo, São Paulo, 03.02.2020. Disponível em: https://saude.estadao.com.br/noticias/geral,operacao-que-trara-de-30-a-40-brasileiros-dewuhan-deve-comecar-nesta-terca-diz-onyx,70003183322. Acessado em: 27 de março de 2020.

7. JORNAL FOLHA DE SÃO PAULO. Governo federal decreta estado de emergência para conter coronavírus no Brasil. Folha de São Paulo, São Paulo, 04.02.2020. Disponível em: https:// www1.folha.uol.com.br/equilibrioesaude/2020/02/governo-decreta-estado-de-emergencia-porcausa-de-surto-do-coronavirus.shtml. Acessado em: 27 de março de 2020.

8. JORNAL O ESTADO DE SÃO PAULO. China constrói hospital em 10 dias para tratar pacientes infectados pelo coronavírus. O Estado de São Paulo, São Paulo, 02.02.2020. Disponível em: https:// saude.estadao.com.br/noticias/geral,china-constroi-hospital-em-10-dias-para-tratar-pacientesinfectados-pelo-coronavirus,70003182805. Acessado em: 27 de março de 2020.

9. ALESSI, GIL. As lições contra o coronavírus que Coreia do Sul e China podem dar ao mundo, incluindo o Brasil. El País, São Paulo, Pandemia de coronavírus. 30.03.2020 Disponível em: https://brasil.elpais.com/internacional/2020-03-30/as-licoes-contra-o-coronavirus-que-coreiado-sul-e-china-podem-dar-ao-mundo-incluindo-o-brasil.html. Acessado em: 30 de março de 2020. 10. G1. Prefeito de Milão admite erro por ter apoiado campanha para cidade não parar no início da pandemia de coronavírus na Itália. O Globo, Rio de Janeiro, Bem Estar. 27.03.2020. Disponível em: https://g1.globo.com/bemestar/coronavirus/noticia/2020/03/27/prefeito-de-milao-admiteerro-por-ter-apoiado-campanha-para-cidade-nao-parar-no-inicio-da-pandemia-de-coronavirusna-italia.ghtml. Acessado em: 28 de março de 2020.

11. JORNAL O GLOBO. Prefeito de Bérgamo diz que duelo entre Atalanta e Valencia "foi uma bomba biológica". O Globo, Rio de Janeiro, Esportes. 25.03.2020. Disponível em: https:// globoesporte.globo.com/futebol/futebol-internacional/futebol-italiano/noticia/prefeito-debergamo-diz-que-duelo-entre-atalanta-e-valencia-foi-uma-bomba-biologica.ghtml. Acessado em: 27 de março de 2020.

12. JORNAL EL PAÍ́S. O mapa do coronavírus: como aumentam os casos dia a dia no Brasil e no mundo. El País, São Paulo, Pandemia de coronavírus. 30.03.2020. Disponível em: https:// brasil.elpais.com/brasil/2020/03/12/ciencia/1584026924_318538.html?rel=friso-portada. Acessado em: 30 de março de 2020. 
13. GÜELL, Oriol. Coronavírus se espalha na Espanha de forma mais rápida e ampla que na Itália. El País, São Paulo, Pandemia de coronavírus. 24.03.2020. Disponível em: https://brasil.elpais.com/ internacional/2020-03-24/coronavirus-se-espalha-na-espanha-de-forma-mais-rapida-e-amplaque-na-italia.html. Acessado em: 29 de março de 2020.

14. BRASIL. Empresa Brasileira de Comunicação. Organização Mundial de Saúde declara pandemia do novo Coronavírus. Disponível em: https://www.unasus.gov.br/noticia/organizacaomundial-de-saude-declara-pandemia-de-coronavirus. Acessado em: 28 de março de 2020.

15. ALVES, Ana Rosa. Casos de Covid-19 no mundo ultrapassam 1 milhão; mortos passam de 51 mil. O Globo, Rio de Janeiro. 02.04.2020. Disponível em: https://oglobo.globo.com/mundo/casosde-covid-19-no-mundo-ultrapassam-1-milhao-mortos-passam-de-51-mil-24346130. Acessado em: 03 de abril de 2020.

16. REVISTA SAÚDE. OMS decreta pandemia do novo coronavírus. Saiba o que isso significa. Editora Abril, São Paulo, Saúde. 13.03.2020. Disponível em: https://saude.abril.com.br/medicina/ oms-decreta-pandemia-do-novo-coronavirus-saiba-o-que-isso-significa/. Acessado em: 28 de março de 2020.

17. G1. EUA têm novo recorde de mortos por coronavírus em um dia: 1.480 . O Globo, Rio de Janeiro. 03.04.2020. Disponível em: https://g1.globo.com/mundo/noticia/2020/04/03/eua-temnovo-recorde-de-mortos-por-coronavirus-em-um-dia-1-480.ghtml. Acessado em: 03 de abril de 2020.

18. G1. Boris Johnson está infectado com o coronavírus. O Globo, Rio de Janeiro. 27.03.2020. Disponível em: https://g1.globo.com/mundo/noticia/2020/03/27/boris-johnson-esta-infectadocom-o-coronavirus.ghtml. Acessado em: 28 de março de 2020.

19. PINHEIRO, Chloé e RUPRECHT, Theo. Coronavírus: primeiro caso é confirmado no Brasil. $O$ que fazer agora?. Editora Abril, São Paulo, Saúde. 04.03.2020. Disponível em: https:// saude.abril.com.br/medicina/coronavirus-primeiro-caso-brasil/. Acessado em: 29 de março de 2020.

20. GANDRA, Alana. Estado do Rio de Janeiro confirma primeiro caso de coronavírus. Agência Brasil, Rio de Janeiro, 05.03.2020. Disponível em: https://agenciabrasil.ebc.com.br/saude/ noticia/2020-03/estado-do-rio-de-janeiro-confirma-primeiro-caso-de-coronavirus-0. Acessado em: 29 de março de 2020.

21. CRUZ, Debora. Sudeste concentra $45 \%$ das viagens de avião feitas pelos brasileiros. O Globo, Rio de Janeiro. 22.10.2015. Disponível em: http://g1.globo.com/economia/noticia/2015/10/ sudeste-concentra-45-das-viagens-de-aviao-feitas-pelos-brasileiros.html. Acessado em: 29 de março de 2020.

22. BARREIRA, Gabriel e GRANDIN, Felipe. Bairros mais caros do Rio lideram casos, mas especialistas temem 'explosão' de Covid-19 nas favelas. O Globo, Rio de Janeiro. 25.03.2020. Disponível em: https://g1.globo.com/rj/rio-de-janeiro/noticia/2020/03/25/bairros-mais-carosdo-rio-lideram-casos-mas-especialistas-temem-explosao-de-covid-19-nas-favelas.ghtml.

Acessado em: 29 de março de 2020.

23. PREFEITURA DO RIO DE JANEIRO. Instituto Pereira Passos. Painel Rio Covid-19. Disponível em: http://www.data.rio/app/painel-rio-covid-19. Acessado em: 29 de março de 2020.

24. UOL. Rio confirma $1^{\underline{a}}$ transmissão local do coronavírus; estado tem 15 casos. Uol, São Paulo, Coronavírus. 12.03.2020. Disponível em: https://noticias.uol.com.br/saude/ultimas-noticias/ redacao/2020/03/12/coronavirus-rio-de-janeiro-transmissao-local.htm. Acessado em: 29 de março de 2020.

25. CAPOBIANCO, Marcela. Governador Witzel decreta fechamento de cinemas, teatros e casas de show. Revista Veja, Rio de Janeiro, Shows. 13.03.2020. Disponível em: https:// vejario.abril.com.br/cidade/governador-witzel-decreto-fechamento-cinema/. Acessado em: 29 de março de 2020. 
26. ÍNDIO DO BRASIL, Cristina. Estado do Rio de Janeiro confirma primeira morte por coronavírus. Agência Brasil, Rio de Janeiro. 19.03.2020. Disponível em: https:// agenciabrasil.ebc.com.br/saude/noticia/2020-03/estado-do-rio-de-janeiro-confirma-primeiramorte-por-coronavirus. Acessado em: 29 de março de 2020.

27. NITAHARA, Akemi. Coronavírus: Rio de Janeiro decreta estado de emergência. Agência Brasil, Rio de Janeiro. 17.03.2020. Disponível em: https://agenciabrasil.ebc.com.br/saude/noticia/ 2020-03/coronavirus-rio-de-janeiro-decreta-situacao-de-emergencia. Acessado em: 30 de março de 2020 .

28. GRELLET, Fabio. Witzel suspende transporte por ônibus e avião para o Rio. Uol, São Paulo, Coronavírus. 19.03.2020. Disponível em: https://noticias.uol.com.br/ultimas-noticias/agenciaestado/2020/03/19/witzel-suspende-transporte-por-onibus-e-aviao-para-o-rio.htm. Acessado em: 30 de março de 2020.

29. JUCÁ, Beatriz. Com projeção de 460.000 infectados no Estado de São Paulo, Brasil endurece combate ao coronavírus. El País, São Paulo, Brasil. 13.03.2020. Disponível em: https:// brasil.elpais.com/brasil/2020-03-14/com-projecao-de-460000-infectados-no-estado-de-saopaulo-brasil-endurece-combate-ao-coronavirus.html. Acessado em: 30 de março de 2020.

30. BRASIL. Empresa Brasileira de Comunicação. Veja as medidas que cada estado está adotando para combater a Covid-19. Agência Brasil, Brasília. 28.03.2020. Disponível em: https:// agenciabrasil.ebc.com.br/saude/noticia/2020-03/veja-medidas-que-cada-estado-esta-adotandopara-combater-covid-19. Acessado em: 30 de março de 2020.

31. SABINO, Marla e BEHNKE, Emiliy. Bolsonaro confronta ação de governadores, que reagem. 0 Estado de São Paulo, São Paulo, 20.03.2020. Disponível em: https://politica.estadao.com.br/ noticias/geral,bolsonaro-alguns-governadores-estao-tomando-decisoes-que-nao-sao-de-suascompetencias,70003241261. Acessado em: 30 de março de 2020.

32. REDE BRASIL ATUAL. Hospital que atendeu Bolsonaro terá que mostrar lista de pacientes com coronavírus. RBA, São Paulo. 21.03.2020. Disponível em: https://www.redebrasilatual.com.br/ politica/2020/03/hospital-bolsonaro-coronavirus-justica/. Acessado em: 30 de março de 2020.

33. VASSALLO, Luis. Bolsonaro violou a lei ao deixar isolamento para teste de coronavírus e cumprimentar manifestantes? O Estado de São Paulo, São Paulo, 15.03.2020. Disponível em: https://politica.estadao.com.br/blogs/fausto-macedo/bolsonaro-violou-a-lei-ao-romper-

isolamento-para-teste-de-coronavirus-e-cumprimentar-manifestantes/. Acessado em: 30 de março de 2020.

34. DELLA COLETTA, Ricardo; FABRINI, Fábio; PASSOS, Úrsula; LINHARES, Carolina. Bolsonaro ignora crise do coronavírus, estimula e participa de ato pró-governo e contra Congresso e STF. Folha de São Paulo, São Paulo, 16.03.2020. Disponível em: https://www1.folha.uol.com.br/poder/ 2020/03/bolsonaro-deixa-isolamento-do-coronavirus-e-de-carro-participa-de-ato-pro-governona-esplanada.shtml. Acessado em: 30 de março de 2020.

35. MARTIN, Nicolas. Estamos apenas no começo da crise econômica. DW, Berlim, Coronavírus. 28.03.2020. Disponível em: https://www.dw.com/pt-br/estamos-apenas-no-come\%C3\%A7o-dacrise-econ\%C3\%B4mica/a-52948694. Acessado em: 30 de março de 2020.

36. VITAL, Danilo. Em liminar, ministro Barroso proíbe campanha "O Brasil não pode parar". Consultório Jurídico, Brasília. 31.03.2020. Disponível em: https://www.conjur.com.br/2020mar-31/liminar-barroso-proibe-campanha-brasil-nao-parar. Acessado em: 31 de março de 2020.

37. SILVEIRA, Daniel e ALVARENGA, Darlan. Trabalho informal avança para $41,3 \%$ da população ocupada e atinge nível recorde, diz IBGE. O Globo, Rio de Janeiro. 30.08.2019. Disponível em: https://g1.globo.com/economia/noticia/2019/08/30/trabalho-informal-avanca-

para-413percent-da-populacao-ocupada-e-atinge-nivel-recorde-diz-ibge.ghtml. Acessado em: 31 de março de 2020.

38. BRASIL. Empresa Brasileira de Comunicação. Senado aprova auxílio de R\$ 600 para trabalhadores informais e autônomos. Agência Brasil, Brasília. 30.03.2020. Disponível em: https:// 
www.gov.br/pt-br/noticias/assistencia-social/2020/03/senado-aprova-auxilio-de-r-600-paratrabalhadores-informais-e-autonomos. Acessado em: 31 de março de 2020.

39. REVISTA VEJA. Trinta pessoas fazem arrastão em supermercado da Zona Leste. Revista Veja, São Paulo, Cidades. 19.03.2020. Disponível em: https://vejasp.abril.com.br/cidades/trintapessoas-arrastao-supermercado-zona-leste/. Acessado em: 31 de março de 2020.

40. MENDONÇA, Heloisa. Governo anuncia 40 bilhões em crédito para financiar salários de pequenas e médias empresas por 2 meses. El País, São Paulo, Pandemia de coronavísrus. 27.03.2020. Disponível em: https://brasil.elpais.com/economia/2020-03-27/governo-anuncia-40bilhoes-em-credito-para-financiar-salarios-de-pequenas-e-medias-empresas-por-2-meses.html. Acessado em: 31 de março de 2020.

41. JORNAL O GLOBO. Cidades têm carreatas pela reabertura do comércio, mas aumenta resistência a atos. O Globo, Rio de Janeiro. 28.08.2019. Disponível em: https://oglobo.globo.com/ sociedade/cidades-tem-carreatas-pela-reabertura-do-comercio-mas-aumenta-resistenciaatos-1-24335984. Acessado em: 31 de março de 2020.

42. ÍNDIO DO BRASIL, Cristina. Witzel prorroga por mais 15 o isolamento social no Rio de Janeiro. Agência Brasil, Rio de Janeiro. 30.03.2020. Disponível em: https://agenciabrasil.ebc.com.br/ saude/noticia/2020-03/witzel-prorroga-por-mais-15-dias-o-isolamento-social-no-rio-de-janeiro. Acessado em: 31 de março de 2020.

43. BASSO, Murilo. Subnotificação dificulta combate à covid-19 no Brasil. DW, Berlim, Coronavírus. 27.03.2020. Disponível em: https://www.dw.com/pt-br/ subnotifica\%C3\%A7\%C3\%A3o-dificulta-combate-\%C3\%A0-covid-19-no-brasil/a-52919120.

Acessado em: 31 de março de 2020.

44. G1, SP tem 201 mortes aguardando resultado do exame de coronavírus: 'parte vai dar positivo', diz secretário. O Globo, Rio de Janeiro. 01.04.2020. Disponível em: https:// g1.globo.com/sp/sao-paulo/noticia/2020/04/01/sp-tem-201-mortes-aguardando-resultado-deexame-de-coronavirus-parte-vai-dar-positivo-diz-secretario.ghtml. Acessado em: 02 de abril de 2020.

45. Brasil. Ministério da Saúde. Secretaria de Vigilância em Saúde. Departamento de Vigilância Epidemiológica. Guia de vigilância epidemiológica / Ministério da Saúde, Secretaria de Vigilância em Saúde, Departamento de Vigilância Epidemiológica. - 7. ed. Brasília: Ministério da Saúde, 2009. 816 p. Disponível em: https://bvsms.saude.gov.br/bvs/publicacoes/ guia_vigilancia_epidemiologica_7ed.pdf Acessado em: 28 de março de 2020.

46. CARMO, M. E.; GUIZARDI, F. L. (2018). O conceito de vulnerabilidade e seus sentidos para as políticas públicas de saúde e assistência social. Cadernos de Saúde Pública, 34 (3), 1-14. Disponível em: http://www.scielo.br/pdf/csp/v34n3/1678-4464-csp-34-03-e00101417.pdf. Acessado em: 28 de março de 2020.

47. CNDSS - Comissão Nacional sobre Determinantes Sociais da Saúde. As Causas Sociais das Iniqüidades em Saúde no Brasil. Rio de Janeiro: Editora Fiocruz, 2008.

220 p. Disponível em: https://bvsms.saude.gov.br/bvs/publicacoes/ causas_sociais_iniquidades.pdf. Acessado em: 28 de março de 2020.

48. BUSS, P. M.; PELLEGRINI FILHO, A. A Saúde e seus Determinantes Sociais. PHYSIS: Revista de Saúde Coletiva, Rio de Janeiro, v. 17, n. 1, p. 77-93, 2007. Disponível em: http://www.scielo.br/ pdf/physis/v17n1/v17n1a06.pdf. Acessado em: 28 de março de 2020.

49. BÉRGAMO, Monica. SP tem 6 vezes mais mortes por coronavírus que a China por dia. Folha de São Paulo, São Paulo, 30.03.2020. Disponível em: https://www1.folha.uol.com.br/colunas/ monicabergamo/2020/03/sp-ja-tem-seis-vezes-mais-mortes-que-a-china-por-dia.shtml.

Acessado em: 31 de março de 2020.

50. BRASIL. Empresa Brasileira de Comunicação. China registra 55 novos casos de covid19. RTP, China, Coronavírus. 27.03.2020. Disponível em: https://agenciabrasil.ebc.com.br/internacional/ 
noticia/2020-03/china-registra-55-novos-casos-importados-de-covid-19. Acessado em: 28 de março de 2020.

\section{RESUMOS}

A Covid-19 surgiu em Wuhan, na China, no final de 2019, e as medidas adotadas de testagem ampla e isolamento social, surtiram efeito para evitar que o coronavírus chegasse nas maiores cidades chinesas. No entanto, apesar do esforço, chegou no país vizinho, a Coreia do Sul, e mais uma vez a estratégia de testagem ampla e isolamento social conseguiram conter o avanço do coronavírus. Parecia que tais medidas seriam suficientes para conter o avanço da epidemia, e que está ficaria restrita ao sudeste asiático. Mas, em um mundo globalizado, com um grande fluxo de pessoas que cruzam fronteiras diariamente, é muito difícil impedir que um vírus, altamente transmissível, alcance todo o planeta, se tornando uma pandemia. Chegou à Europa, América do Norte, e o cenário mundial vai se tornando a cada dia mais trágico, pois novos casos se multiplicam na África e América do Sul. Fatores socioeconômicos são determinantes no processo saúde-doença e a estratégia de isolamento social, adotada como medida de redução da vulnerabilidade da população, esbarra em um quadro social complexo agravado pela crise econômica que atinge países em desenvolvimento, como o Brasil.

A la fin de 2019, la Covid-19 est apparue dans la ville chinoise de Wuhan, et des mesures telles que des tests massifs et l'isolement social ont été efficaces par rapport son arrivée aux villes les plus grands. Malgré les efforts, le pays voisin de la Chine, la Corée du Sud, a été infectée, et les mêmes mesures ont été adoptées avec succès. Si l'on pourrait penser qu'il s'agissait d'un phénomène borné au Sud-ouest Asiatique, les flux des personnes et les croisements de frontières propres à la mondialisation, ainsi que la capacité d'être un virus facilement transmissible, ont créé le scenario typique d'une pandémie. De l'Europe à l'Amérique du Nord, et de l'Afrique à l'Amérique du Sud, la situation est devenue tragique - surtout dans un pays en voie de développement comme le Brésil, dont les facteurs socio-économiques sont responsables d'aggraver la crise.

Covid-19 surgió en Wuhan, China, a fines de 2019, y las medidas adoptadas para pruebas exhaustivas y aislamiento social han tenido un efecto para evitar que el coronavirus llegue a las ciudades chinas más grandes. Sin embargo, a pesar del esfuerzo, llegó al país vecino, Corea del Sur, y una vez más la estrategia de pruebas exhaustivas y aislamiento social logró contener el avance del coronavirus. Parecía que tales medidas serían suficientes para contener la propagación de la epidemia, y que se limitaría al sudeste asiático. Pero en un mundo globalizado, con un gran flujo de personas que cruzan las fronteras diariamente, es muy difícil evitar que un virus altamente transmisible llegue a todo el planeta, convirtiéndose en una pandemia. Llegó a Europa, América del Norte, y el escenario mundial se está volviendo cada vez más trágico, a medida que los nuevos casos se multiplican en África y América del Sur. Los factores socioeconómicos son decisivos en el proceso de salud-enfermedad y la estrategia de aislamiento social, adoptada como medida para reducir la vulnerabilidad de la población, se enfrenta a una compleja situación social agravada por la crisis económica que afecta a los países en desarrollo, como Brasil.

Covid-19 arose in Wuhan, China, in the end of 2019, and the measures taken about broad testing and social isolation, have the proposed to avoid the virus to get to the major chinese cities. 
However, despite the effort, the virus arrived at the neighboring country, South Korea, and again the strategy of broad testing and social isolation have managed to contain the advance of the coronavirus. It seemed that these actions would be enough to contain the progress of the epidemic. But, in a globalized world, with a large flow of people who cross borders daily, it's hard to stop a virus, highly transmissible, to reach the whole world, becoming a pandemic. It arrived in Europe, North America, and the world stage is becoming increasingly tragic, because more cases multiplied in Africa and South America. Socioeconomic factors are crucial in the healthdisease process and the social isolation strategy, adopted as a measure to reduce the vulnerability of the population, runs into a complex social situation aggravated by the economic crisis affecting developing countries, like Brazil.

\section{ÍNDICE}

Keywords: pandemic, Covid-19, Brazil, socioeconomic factors, public policies

Palabras claves: pandemia, Covid-19, Brasil, fatores socioeconômicos, políticas públicas.

Mots-clés: pandémie, Covid-19, Brésil, facteurs socio-économiques, politiques publiques.

\section{AUTOR}

HEITOR SOARES DE FARIAS

PPGEO/UFRRJ 